\title{
R Wave Notched by ECG Finding
}

National Cancer Institute

\section{Source}

National Cancer Institute. R Wave Notched by ECG Finding. NCI Thesaurus. Code C90444.

An electrocardiographic finding of an $\mathrm{R}$ wave variant in which there is a small deflection of the R wave, with chang ing polarity, within the QRS complex. 